Article

\title{
Nighttime Sleep Awakening Frequency and Its Consistency Predict Future Academic Performance in College Students
}

\author{
Ghee Wee Ho ${ }^{1, *}$, Zhenzhi Yang ${ }^{1}$, Linna Xing ${ }^{1}$, , Ken Kang-Too Tsang ${ }^{2}$, Huada Daniel Ruan ${ }^{3}$ and Yu Li ${ }^{1, *}$ \\ 1 Applied Psychology Programme, Division of Science and Technology, BNU-HKBU United International College, \\ 2000 Jintong Rd, Tangjiawan, Zhuhai 519087, China; jennyyang@uic.edu.cn (Z.Y.); \\ solnalnxing@uic.edu.cn (L.X.) \\ 2 Statistics Programme, Division of Science and Technology, BNU-HKBU United International College, \\ Zhuhai 519087, China; k2zeng@icloud.com \\ 3 Environmental Science Programme, Division of Science and Technology, BNU-HKBU United International College, \\ Zhuhai 519087, China; hruan@uic.edu.cn \\ * Correspondence: gheeho@uic.edu.cn (G.W.H.); yuli@uic.edu.cn (Y.L.)
}

Citation: Ho, G.W.; Yang, Z.; Xing, L.; Tsang, K.K.-T.; Ruan, H.D.; Li, Y. Nighttime Sleep Awakening Frequency and Its Consistency Predict Future Academic Performance in College Students. Int. J. Environ. Res. Public Health 2022, 19, 2933. https://doi.org/10.3390/ ijerph19052933

Received: 29 December 2021 Accepted: 7 February 2022

Published: 2 March 2022

Publisher's Note: MDPI stays neutral with regard to jurisdictional claims in published maps and institutional affiliations.

Copyright: (C) 2022 by the authors. Licensee MDPI, Basel, Switzerland. This article is an open access article distributed under the terms and conditions of the Creative Commons Attribution (CC BY) license (https:// creativecommons.org/licenses/by/ $4.0 /)$.

\begin{abstract}
Although the relationship between sleep and academic performance has been extensively examined, how sleep predicts future academic performance (e.g., 2-3 years) remains to be further investigated. Using wearable smartwatches and a self-report questionnaire, we tracked sleep activities of 45 college students over a period of approximately half a month to see whether their sleep activities predicted their academic performance, which was estimated by grade point average (GPA). Results showed that both nighttime sleep awakening frequency and its consistency in the tracking period were not significantly correlated with the GPA for the courses taken in the sleep tracking semester (current GPA). However, both nighttime sleep awakening frequency and its consistency inversely predicted the GPA for the rest of the courses taken after that semester (future GPA). Moreover, students with more difficulty staying awake throughout the day obtained lower current and future GPAs, and students with higher inconsistency of sleep quality obtained lower future GPA. Together, these findings highlight the importance of nighttime sleep awakening frequency and consistency in predicting future academic performance, and emphasize the necessity of assessing the consistency of sleep measures in future studies.
\end{abstract}

Keywords: sleep; academic performance; grade point average; college students; wearable device; longitudinal; nighttime sleep awakening

\section{Introduction}

As a necessity for humans, healthy sleep plays an essential role in maintaining normal brain and cognitive functions [1-5]. For example, it has been revealed that sleep facilitates language learning [6], and consolidates memory [7,8]. Extant studies have provided mounting evidence that individuals who are suffering from sleep disturbances or deprivation exhibit not only severe impairments on various cognitive functions [9-16], but also aberrances in neural structure and activity [17-23]. In the context of school education, sleep problems or disturbances are prevalent in students of all ages, ranging from primary school [24-26] to college [27-30]. The negative influences of sleep problems on academic performance have also been reported in both children and college students, even though the mechanisms underlying the relationships remain to be explored. It has been widely observed that various sleep-related measures, such as sleep duration and sleep quality, are associated with academic performance [23,31-33], indicating the importance of normal sleep patterns in school education.

For college students, grade point average (GPA) is one of the most important indicators reflecting the success of college education. It is associated with various crucial aspects, including intelligence, socio-economic status, schooling quality, learning motivation, and 
health problems $[34,35]$. In the past two decades, much research has been conducted to examine the associations between sleep and GPA $[33,36,37]$. There is increasing evidence that GPA can, to some degree, be predicted by certain sleep measures, including sleep duration [38-45] and sleep quality [42,43,46-51].

In the extant literature, most studies investigating the relationships between sleep and academic performance used averages of sleep measures in a period as indexes in data analysis and interpretation [41,42,48,49,52-54]. Beyond these traditional sleep measures, sleep consistency or variability have been receiving more and more attention in recent years $[41,43,44,53,55-58]$. The consistency of a sleep measure is usually estimated by standard deviation or standard error of the mean in a period (e.g., a few weeks), where a higher value denotes lower consistency or high variability. In the studies of college students, Taylor et al. [41] found that sleep duration consistency estimated by standard deviation showed a significantly negative relationship with GPA. Smarr [58] found that sleep duration consistency estimated by standard error of the mean was negatively associated with class performance. Okano et al. [43] found that sleep duration consistency estimated by standard deviation was negatively associated with GPA. Sridhar et al. [44] found that sleep consistency indexed by standard deviation was negatively correlated with homework grades. Using a sleep regularity index, Phillips et al. [53] found that standard deviations of sleep onset times and wake-up times were negatively correlated with GPA. Collectively, lower sleep consistency and higher variability are associated with lower academic performance, demonstrating that sleep consistency can be a reliable predictor of academic performance.

It is worth noting that these studies have primarily focused on how sleep predicts GPA for the courses taken by students just after sleep tracking. There are only a few studies that used a longitudinal design to examine the relationships between sleep measures and long-term academic performance, such as GPA two years later [59-63]. Of these studies, three studies reported significant associations between sleep and long-term academic performance. Wong et al. [59] found that sleep duration of the first semester predicted the overall GPA across three semesters in college students. Galambos et al. [60] found that overall GPA for four years courses was lower when bedtimes were later in college students. Stormark et al. [63] found that persistent sleep problems across several years elevated the risk of academic performance in children. These findings suggest that sleep activities can serve as good indicators of future or long-term academic performance.

Among the studies examining associations between sleep and academic performance, most used self-report questionnaires, such as the Pittsburgh Sleep Quality Index [64] and in-house ones, to estimate sleep activities. Results from self-reports are inherently subjective, and participants' responses can be influenced by individual differences in reporting standards, and concurrent emotional states. The field calls for objective approaches. Polysomnography is thought to provide an objective way for tracking sleep activities, and has been widely used in previous research [65-69]. However, its use in laboratories, to a certain degree, has an impact on ecological validity. In recent years, wearable smart devices have been invented and widely used to track physiological activities, such as heart rate, calorie consumption, walking steps, and sleep patterns (e.g., duration, onset time, and offset time). Wearable smart devices can be used at home and school dormitories where participants feel familiar and comfortable, demonstrating high ecological validity. Sleep measures provided by smart devices are estimated based on implemented computer algorithms; individuals' sleep characteristics can therefore be derived with the very same standards. Because of this, sleep measures generated from the devices could be more objective compared to self-report questionnaires. A few studies have already employed wearable devices to track sleep activity [43,44,50,70-73]. Out of these studies, four examined the relationships between wearable-device-based sleep measures (e.g., duration and quality) and academic performance. Okano et al. [43] found that better sleep quality, longer sleep duration, and greater sleep consistency were associated with better grades. Sridhar et al. [44] found a non-significant association between average sleep duration and average grades on weekly homework assignments, but a significantly negative association between 
sleep variability and average homework grades. Wang et al. [73] found that wearable devices with feedback on sleep quality improved both sleep and academic outcomes in students. Adelantado-Renau et al. [50] used both wearable devices and self-reported measures, and found that sleep duration estimated by devices was associated with verbal ability, and self-reported sleep quality was associated with GPA. These provide strong evidence of the usability of wearable devices in predicting academic performance.

In this longitudinal study, we aimed to examine the association between sleep measures and GPA in college students. We used wearable smartwatches to track students' sleep activities in a short period, and a self-report questionnaire to record students' subjective feelings about their sleep and daily performance, and collected both their short-term and long-term GPAs. We considered both averages of sleep measures in the sleep tracking period, and their consistency estimated by standard deviations [43], as these two different types of measures could provide a bigger picture of sleep activity. Considering the exploratory nature of this study, we generally hypothesized that sleep measures and their consistency would predict students' academic performance estimated by GPA. Correlation and mediation analyses were used to determine the relationships between sleep and GPA. The design of the present study is innovative in that it used objective and subjective sleep measures and their consistency, and also considered short-term and long-term academic performance.

\section{Methods and Materials}

\subsection{Participants}

Two separate groups of students volunteered to participate in this study. Group 1 consisted of 25 students (age range, 19.09-20.75 years; mean age, 20.11 years; 17 females), whereas the second group consisted of 22 students (age range, 18.67-21.15 years; mean age, 19.93; 17 females). All the participants were undergraduate students majoring in Applied Psychology in BNU-HKBU United International College. None of them reported any neurological impairments in the past, and all of them had normal hearing and normal or corrected-to-normal vision. The participants were notified that if there were any stressful life events (e.g., important examinations or death of family members) or any somatic or mental diseases (e.g., gastric ulcer, body injury, and clinical depression and anxiety) in the sleep tracking period, they were asked to report to the investigators by filling in a self-report questionnaire (see below). None of them reported any on these. Two students failed to complete the study, and their data were excluded from data analyses. The Human Research Ethics Committee of BNU-HKBU United International College approved this study. A consent form was obtained from participants prior to the study.

\subsection{Procedure}

The two groups of students were being tracked separately. Each of the participants was asked to wear a smartwatch, the "Huawei Honor Watch S1" issued in 2016, to track their daily heart rate (mean, minimum, and maximum), sleep score (calculated with algorithms implemented), sleep time, deep/light/REM sleep time (min), and nighttime sleep awakening frequency. Algorithms and sensors implemented in the smartwatch were used to track individuals' physiological activities (see the details at https://www. smartwatchspecifications.com/devices/huawei-honor-watch-s1-glory-watch-s1/ accessed on 20 December 2021). This device was widely used to track their heart activities (e.g., rate) and sport activities (e.g., walking steps [74,75]), and has previously demonstrated excellent reliability and sensitivity [74-76]. It was therefore chosen to be the instrument for monitoring sleep activities. Both groups were being tracked for a period of approximately two weeks, based on the restrictions on the students' academic schedules. Both groups were tracked in the middle of the first semester of their second-year study. Group 1 participants were tracked for 13 days, whereas Group 2 participants were tracked for 17 days. On each day of the tracking period, a self-report questionnaire was administered to the participants to collect additional information, including self-reported sleep quality $(0-10$; 0 denotes 
worst, and 10 excellent), feeling of tiredness (0-10; 0 denotes worst, and 10 excellent), and whether the participants struggled to keep awake during daytime (0 Yes, 1 No).

After tracking the participants' sleep, and collecting their answers of the self-report questionnaire, their GPAs for compulsory psychology courses were collected. For each group, we only included compulsory psychology courses to make sure that their GPAs were given based on the same marking criteria. We calculated two types of GPAs, the GPA for the semester courses (current GPA, i.e., the compulsory courses taken in the semester when students were participating in the study: Biological Psychology, Research Methods in Psychology, and Developmental Psychology for Group 1 students; and Introduction to Psychology for Group 2 students; 2 months temporal distance between the sleep tracking period and the final examination of the courses), and the GPA for the courses after that semester (future GPA, i.e., all the compulsory psychology courses taken after the semester: 10 courses for Group 1 and 13 courses for Group 2; 2.5 years temporal distance between the sleep tracking period and graduation). For the calculation of GPA, marks on final examination, mid-term quiz, and attendance were considered. The GPA for final year project (each student was required to complete a research thesis) were excluded due to its highly subjective rating system. The current GPA was used to determine whether sleep measures could be an indicator of the present academic achievement of students, whereas the future GPA was used to determine whether sleep measures could predict their long-term academic achievement.

\subsection{Data Analysis}

We adopted two approaches for the analyses. First, for each of the sleep measures and self-reported indexes, the data were averaged across the tracking period to generate an overall estimate. We then correlated average values for each of the sleep measures and self-reported indexes to the current and future GPAs. We found that both nighttime sleep awakening frequency and self-reported wakefulness were significantly correlated with the current and future GPAs. Furthermore, nighttime sleep awakening frequency and self-reported wakefulness were also correlated (see Results). To examine these relationships, we further conducted a mediation analysis, specifically by employing the PROCESS macro ([77]) for IBM SPSS Statistics 25.0, to determine whether self-reported wakefulness mediated the influences of sleep awakening frequency on GPA. Second, for each of the sleep measures and self-reported indexes, we calculated the standard deviation of the data in the sleep tracking period to generate an index of consistency (see [43] for a similar approach). Note that for each measure, a large standard deviation denotes low consistency.

\section{Results}

The mean of the current GPA was 3.06 (range, 1.67-4.00; SD, 0.51), and the mean of the future GPA was 3.08 (range, 1.89-3.77; SD, 0.50). The correlation between the two types of GPAs was statistically significant $(r=0.758, p<0.001)$, indicating a high stability of academic achievement. The statistical details of sleep measures and self-reported measures are presented in Table 1. We first conducted correlational analyses based on the averaged data across the tracking period (see the correlations below the diagonal line in Table 2). The results showed that nighttime sleep awakening frequency was negatively correlated with the future GPA $(r=-0.387, p=0.009)$, but not with the current GPA $(r=-0.165, p=0.279$; Figure 1$)$. The correlation between nighttime sleep awakening frequency and the future GPA was still significant after controlling for the current GPA $(r=-0.408, p=0.006)$. Hierarchical regression analysis confirmed this by revealing that nighttime sleep awakening frequency significantly accounted for the variance of the future GPA $(7.1 \%, p=0.006)$ beyond the influences of the current GPA (57.5\%; Table 3). 
Table 1. Basic statistical results of average and consistency of sleep measures provided by the wearable device and self-reported measures.

\begin{tabular}{cccccccccc}
\hline & \multicolumn{3}{c}{ Average across Tracking Period } & \multicolumn{2}{c}{ Consistency across Tracking Period } \\
\cline { 2 - 8 } Measures & Min & Max & Mean & SD & Min & Max & Mean & SD \\
Heart rate & 43.54 & 76.92 & 57.02 & 6.66 & 1.41 & 12.09 & 4.41 & 2.15 \\
Heart rate minimum & 36.46 & 62.00 & 52.05 & 5.25 & .83 & 23.48 & 5.00 & 4.67 \\
Heart rate maximum & 51.23 & 144.62 & 122.98 & 14.31 & 4.70 & 30.57 & 15.90 & 6.21 \\
Sleep score & 72.53 & 119.92 & 80.36 & 6.78 & 1.00 & 13.02 & 5.77 & 2.35 \\
Sleep time (mins) & 305.00 & 491.46 & 404.36 & 45.23 & 21.82 & 194.82 & 87.07 & 34.83 \\
Deep sleep time (mins) & 97.29 & 249.77 & 135.21 & 27.03 & 16.74 & 77.36 & 39.68 & 14.99 \\
Light sleep time (mins) & 128.62 & 247.71 & 183.62 & 29.51 & 20.97 & 128.41 & 49.85 & 20.96 \\
Rapid eye movement time (mins) & 54.94 & 116.31 & 83.17 & 13.79 & 16.93 & 74.80 & 30.46 & 11.15 \\
Awakening frequency & 0 & 2.29 & 0.81 & 0.49 & 0 & 2.14 & 0.85 & 0.37 \\
Self-reported sleep quality & 2.85 & 8.69 & 5.83 & 1.22 & 0.80 & 3.69 & 1.93 & 0.70 \\
Self-reported daytime tiredness & 1.69 & 8.12 & 5.19 & 1.28 & 0.70 & 3.64 & 2.02 & 0.61 \\
Self-reported daytime wakefulness & 0 & 1.00 & 0.66 & 0.30 & 0 & 0.96 & 0.40 & 0.26 \\
\hline
\end{tabular}
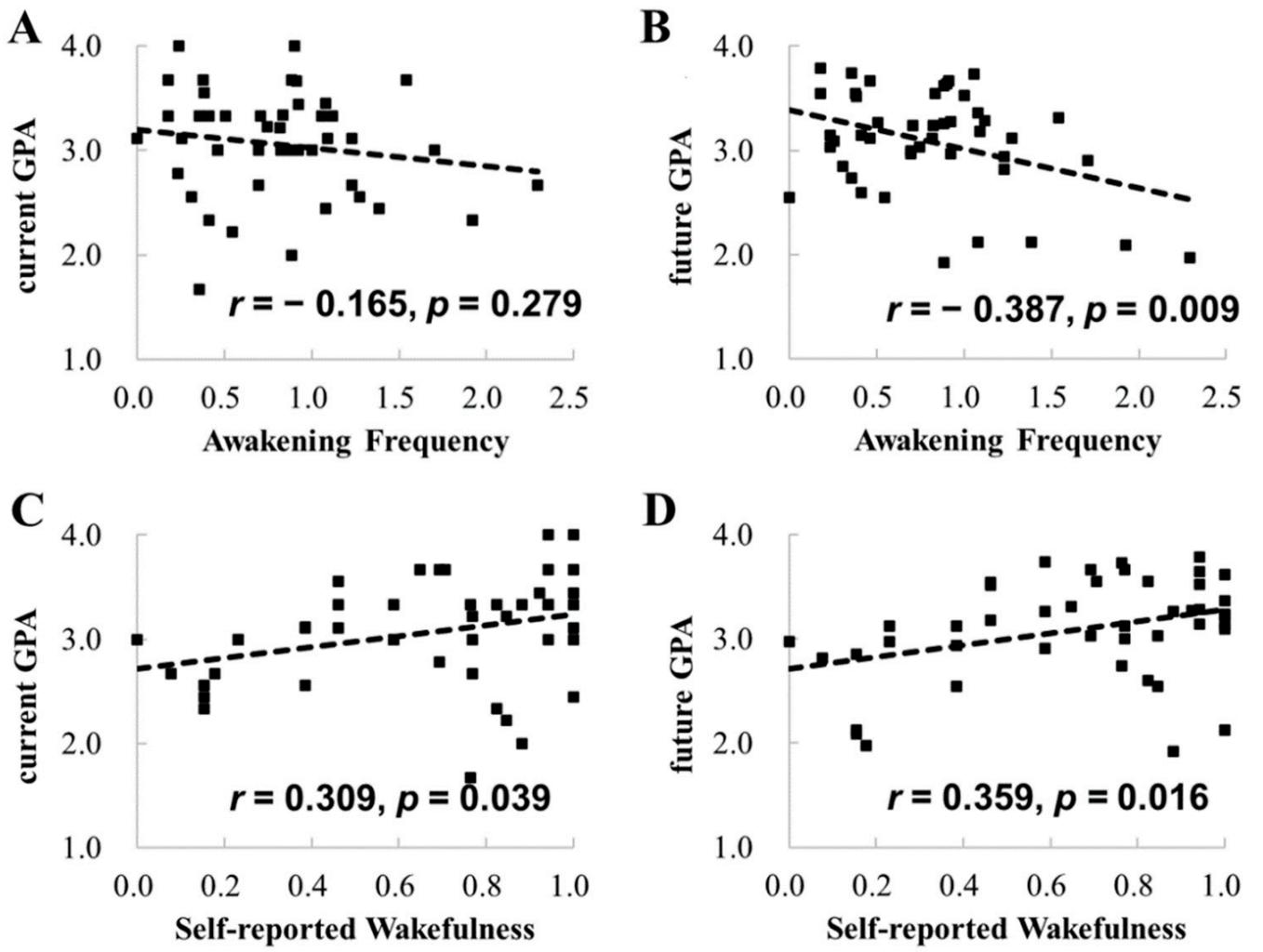

Figure 1. Correlations between awakening frequency and the current and future GPAs (A,B), and correlations between self-reported wakefulness and the current and future GPAs (C,D). 
Table 2. Pearson's correlations among measures for averaged data (below the diagonal line) and measures for consistency (above the diagonal line).

\begin{tabular}{ccccccccccccccccc}
\hline & $\mathbf{1}$ & $\mathbf{2}$ & $\mathbf{3}$ & $\mathbf{4}$ & $\mathbf{5}$ & $\mathbf{6}$ & $\mathbf{7}$ & $\mathbf{8}$ & $\mathbf{9}$ & $\mathbf{1 0}$ & $\mathbf{1 1}$ & $\mathbf{1 2}$ & $\mathbf{1 3}$ & $\mathbf{1 4}$ \\
\hline 1 & & $0.758^{* * *}$ & 0.012 & -0.041 & 0.096 & -0.038 & -0.219 & $-0.268^{\Psi}$ & -0.022 & -0.053 & -0.133 & -0.237 & $-0.258^{\Psi}$ & -0.188 \\
2 & $0.758^{* * *}$ & & -0.076 & -0.110 & 0.081 & -0.031 & -0.187 & -0.143 & 0.000 & -0.052 & $-0.312^{*}$ & $-0.323^{*}$ & $-0.280^{\Psi}$ & -0.089 \\
3 & -0.044 & -0.141 & & $0.339^{*}$ & 0.168 & 0.055 & -0.126 & -0.160 & -0.071 & -0.072 & -0.210 & -0.123 & -0.071 & 0.009 \\
4 & 0.081 & 0.040 & $0.473^{* * *}$ & & 0.045 & 0.203 & -0.162 & -0.132 & -0.228 & -0.205 & -0.113 & -0.063 & 0.001 & 0.194 \\
5 & -0.212 & -0.162 & $-0.364^{*}$ & 0.181 & & -0.219 & -0.032 & 0.021 & -0.052 & 0.000 & -0.203 & 0.050 & 0.098 & 0.206 \\
6 & -0.040 & -0.061 & $0.389^{* *}$ & $-0.417^{* *}$ & $-0.692^{* * *}$ & & $0.305^{*}$ & $0.328^{*}$ & 0.070 & $0.308^{*}$ & 0.245 & -0.062 & -0.170 & -0.101 \\
7 & -0.107 & 0.110 & $-0.360^{*}$ & -0.176 & 0.123 & 0.094 & & $0.642^{* * *}$ & $0.748^{* * *}$ & $0.436^{* *}$ & $0.260^{\Psi}$ & $0.406^{* *}$ & $0.318^{*}$ & 0.118 \\
8 & $-0.287^{\Psi}$ & -0.125 & -0.243 & $-0.328^{*}$ & 0.145 & 0.143 & $0.572^{* * *}$ & & $0.393^{* *}$ & $0.658^{* * *}$ & 0.153 & $0.305^{*}$ & 0.148 & 0.156 \\
9 & 0.119 & $0.267^{\Psi}$ & -0.227 & 0.078 & 0.000 & -0.003 & $0.715^{* * *}$ & -0.094 & & $0.395^{* *}$ & 0.212 & 0.203 & 0.163 & -0.113 \\
10 & -0.006 & 0.053 & -0.097 & -0.080 & 0.107 & 0.085 & $0.595^{* * *}$ & 0.186 & $0.348^{*}$ & & $0.270^{\Psi}$ & 0.100 & -0.030 & -0.125 \\
11 & -0.165 & $-0.387^{* *}$ & 0.066 & -0.044 & 0.131 & 0.095 & 0.075 & -0.056 & 0.134 & 0.086 & & $0.265^{\Psi}$ & 0.228 & 0.017 \\
12 & 0.122 & -0.030 & -0.132 & -0.102 & -0.014 & 0.018 & $0.277^{\Psi}$ & 0.148 & $0.298^{*}$ & 0.181 & -0.068 & & $0.792^{* * *}$ & $0.629^{* * *}$ \\
13 & -0.053 & -0.189 & -0.182 & -0.225 & 0.004 & 0.096 & 0.167 & 0.095 & 0.210 & -0.118 & 0.121 & $0.611^{* * *}$ & \\
14 & $0.309^{*}$ & $0.359^{*}$ & -0.103 & 0.094 & -0.243 & 0.078 & $0.356^{*}$ & 0.057 & $0.459 * *$ & 0.073 & $-0.331^{*}$ & $0.407^{* *}$ & 0.123 & $0.548^{* * *}$
\end{tabular}

Note: 1, current GPA; 2, future GPA; 3, heart rate; 4, heart rate minimum; 5, heart rate maximum; 6, sleep score 7, sleep time (mins); 8 , deep sleep time (mins); 9, light sleep time (mins); 10, rapid eye movement time (mins) 11, awakening frequency; 12 , self-reported sleep quality; 13 , self-reported daytime tiredness; 14 , self-reported daytime wakefulness; ${ }^{\Psi} p<0.10,{ }^{*} p<0.05,{ }^{* *} p<0.01,{ }^{* * *} p<0.001$.

Table 3. Hierarchical regression analyses predicting cumulative GPA from semester GPA and nighttime sleep awakening frequency.

\begin{tabular}{lccc}
\hline & & \multicolumn{2}{c}{ Future GPA } \\
\cline { 3 - 4 } Step & Variables & $\mathbf{R}^{2}$ & $\Delta \mathbf{R}^{2}$ \\
\hline 1 & Current GPA & 0.575 & $0.575^{* * *}$ \\
2 & Nighttime sleep awakening frequency & 0.646 & $0.071^{* *}$ \\
2 & Consistency of nighttime sleep awakening frequency & 0.620 & $0.045^{*}$ \\
\hline Note. ${ }^{*} p<0.05 .{ }^{* *} p<0.01 .{ }^{* * *} p<0.001$. & &
\end{tabular}

For the correlations between GPA and self-reported measures, we found that self-reported wakefulness was positively correlated with both the current GPA $(r=0.309, p=0.039)$ and the future GPA $(r=0.359, p=0.016$; Figure 1). Moreover, we found that nighttime sleep awakening frequency was negatively correlated with self-reported wakefulness $(r=-0.331, p=0.026)$. The findings indicate a possibility that self-reported wakefulness mediated the influences of nighttime sleep awakening frequency on the future GPA. To examine the possibility, we conducted a mediation analysis. As displayed in Figure 2, Path $c$ denotes the total effects (mediated and direct effects) of awakening frequency on the future GPA, and Path $c^{\prime}$ denotes the direct effect of nighttime sleep awakening frequency on the future GPA. The mediated effect, i.e., the effect of awakening frequency on the future GPA via self-reported wakefulness, is determined by the difference between Path $c$ and Path $c^{\prime}$ or the product of Path $a$ and Path $b$. The mediation analysis revealed that Path $c^{\prime}$ was statistically significant (Figure 2), but the difference between Path $c$ and Path $c^{\prime}$ was statistically insignificant (Sobel test, $z=-1.369$, $p=0.171$ ). These findings suggests that self-reported wakefulness did not significantly mediate the influences of nighttime sleep awakening frequency on the future GPA. 


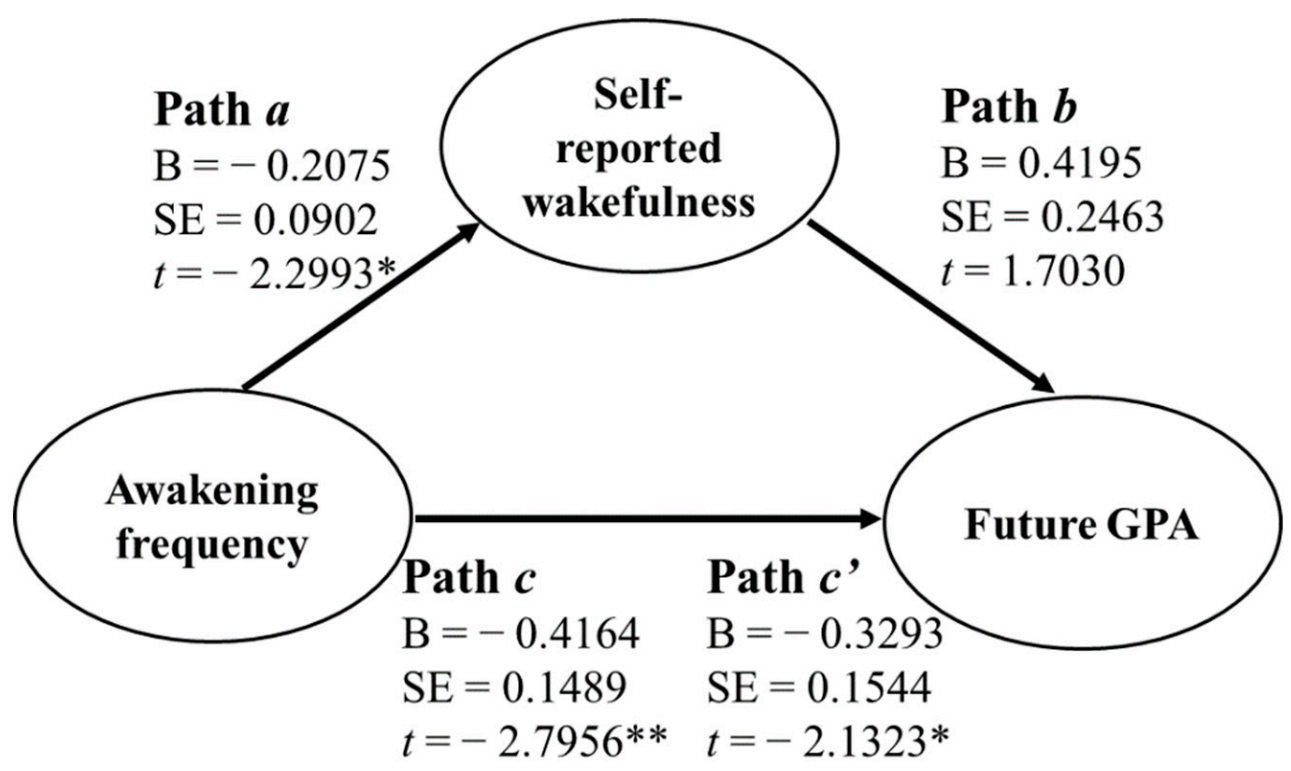

Figure 2. Results of mediation analysis. Path $a$ denotes the effect of awakening frequency on selfreported wakefulness. B, regression coefficient. SE, standard error. Path $b$ denotes the impact of self-reported wakefulness on the future GPA. Paths $a$ and $b$ denote the mediated or indirect effect of awakening frequency on the future GPA via self-reported wakefulness. Path $c$ denotes the total effects (mediated and direct effects) of awakening frequency on the future GPA. Path $c^{\prime}$ denotes the direct effect of awakening frequency on the future GPA. ${ }^{*} p<0.05$. ${ }^{* *} p<0.01$.

We then conducted correlational analyses based on the consistency of each sleep measure estimated by the standard deviation of the data in the tracking period (see the correlations above the diagonal line in Table 2). The results showed that the consistency of nighttime sleep awakening frequency was positively correlated with the future GPA $(r=-0.312, p=0.037$; Figure 3$)$, but not with the current GPA $(r=-0.133, p=0.382)$, indicating that the higher the consistency of nighttime sleep awakening frequency, the higher the future GPA. The correlation between the consistency of nighttime sleep awakening frequency and the future GPA was still significant after controlling for the current GPA $(r=-0.326, p=0.031)$. Hierarchical regression analysis confirmed this by revealing that that the consistency of nighttime sleep awakening frequency significantly accounted for the variance of the future GPA $(4.5 \%, p=0.031)$ beyond the influences of the current GPA (Table 3).

Furthermore, we found that self-reported sleep quality was negatively correlated with the future GPA ( $r=-0.323, p=0.031$; Figure 3$)$, but not with the current GPA $(r=-0.237$, $p=0.117$ ), indicating that inconsistent sleep time in a period is not associated with lower immediate academic achievement, but long-term academic achievement. 
A

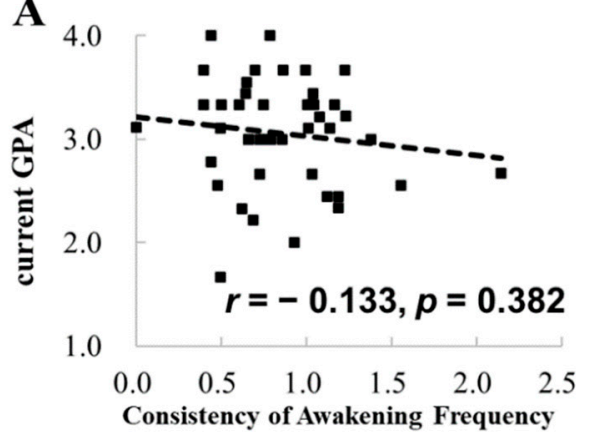

C

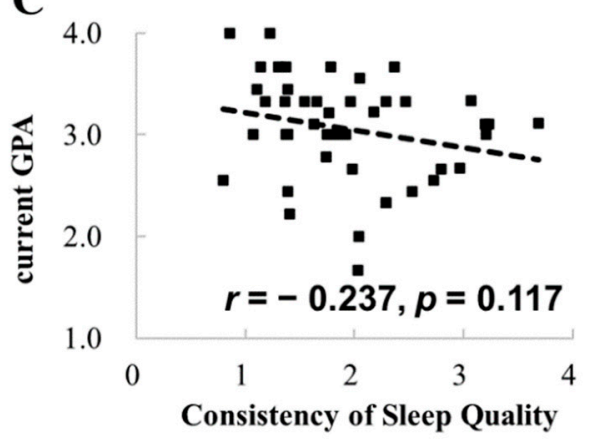

B

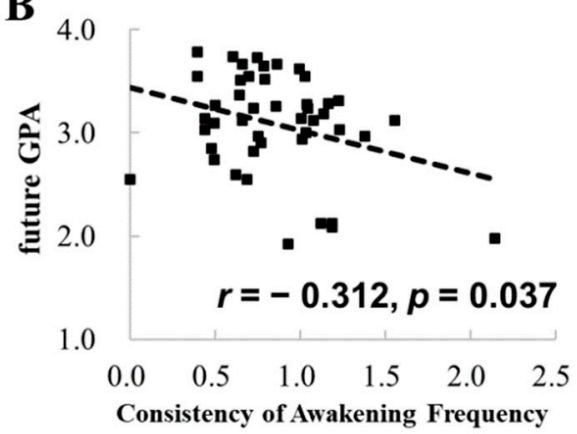

D

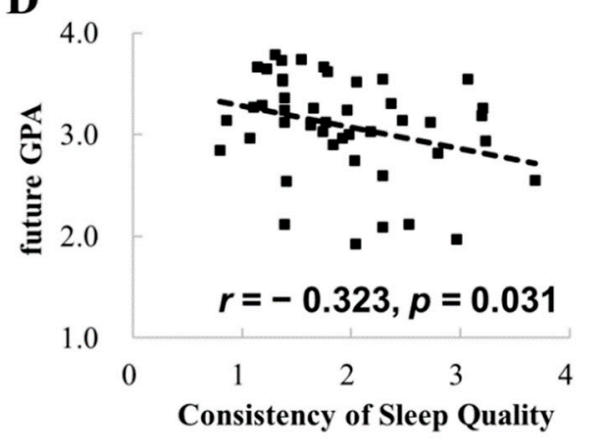

Figure 3. Correlations between the consistency of awakening frequency and the current and future GPAs (A,B), and correlations between the consistency of self-reported sleep quality and the current and future GPAs $(\mathbf{C}, \mathbf{D})$.

\section{Discussion}

In the present longitudinal study, we used wearable smart wrist watches to examine whether sleep is associated with GPA in college students. We found that nighttime sleep awakening frequency and consistency were negatively correlated with the future GPA, that self-reported daytime wakefulness was correlated with both semester and future GPAs, and that self-reported sleep quality consistency was negatively correlated with the future GPA. These results and possible implications are discussed below.

We found that students with more frequent nighttime sleep awakenings tended to get lower GPAs for future college courses. To the best of our knowledge, this relationship was reported for the first time. Previous studies have tried to measure nighttime sleep awakenings in children [78-82] and college students [83], but these did not reveal significant associations with academic performance, except for El-Sheikh et al. [79]. In the study, El-Sheikh et al. [79] monitored sleep disruptions by using actigraphs in primary school children, and found that sleep quality and duration, which was significantly contributed to by duration after sleep onset, were associated with children's academic functioning reported by their teachers, despite a direct correlation not being observed between duration after sleep onset and children's academic functioning. Velten-Schurian et al. [80] found that in children diagnosed with insomnia, those with more parent-reported nighttime awakenings tend to exhibit more daytime sleepiness. It has been previously reported that college students' daytime sleepiness is associated with GPA [40,84] and exam struggles [85]. The current study revealed that college students who have more difficulties staying awake throughout the day tended to get lower current and future GPAs, indicating the predictive power of daytime sleepiness in concurrent and future academic performance.

Considering that self-reported daytime wakefulness was significantly associated with the future GPA, we further conducted a mediation analysis to determine whether daytime wakefulness mediated the influences of awakening frequency on the future GPA. The results showed that the mediated effect was not significant, indicating that daytime wakefulness and nighttime sleep awakening frequency are not fully overlapped with each other in 
contributing to academic performance. Other factors, such as daily schedule, emotional arousal, and caffeine intake, may play an important role in between, which remains to be investigated.

The future GPA was significantly correlated not only with nighttime sleep awakening frequency, but also with its consistency. Sleep consistency or variability has been found to be associated with academic performance for sleep duration $[41,43,44,58]$ and sleep onset and wake-up times [53]. Extending these studies, the current study provided a new indicator of academic performance. More importantly, unlike these studies in which a significant relationship between sleep consistency and concurrent GPA was revealed, we determined that the consistency of nighttime sleep awakening frequency predicted future GPA. It suggests that the consistency of nighttime sleep awakening frequency could serve as a longitudinal indicator of academic performance. There is a possible reason why we did not find correlations between these awakening frequency measures and the current GPA: the number of the courses for calculating the current GPA was much less than that of the courses for calculating the future GPA, and thus led to an unreliable estimate for academic performance.

It is worth noting that, similar to the current study, Okano et al. [43] and Sridhar et al. [44] also used wearable activity trackers to monitor sleep activity. Previous studies have demonstrated that electronic devices can accurately track sleep activity in students [50,70-73]. For example, Beattie et al. [71] demonstrated that algorithms used for Fitbit wearable devices accurately estimated sleep duration and quality in adults with normal sleep. These endeavors demonstrate an objective way to estimate sleep activities that traditionally could only be measured with subjective self-report surveys or questionnaires from students or their parents. Therefore, using electronic devices, especially wearable wrist watches or trackers (e.g., Fitbit and the one used here), can be considered an alternative for researchers to investigate relationships between academic performance and sleep activity.

For sleep quality, previous studies have revealed that sleep quality estimated by selfreported Pittsburgh Sleep Quality Index [64] is associated with concurrent GPA [42,47-49,51]. Here, we found that the consistency of self-reported sleep quality was positively correlated with the future GPA, but not correlated with the current GPA. In other words, students with consistent sleep quality get a higher future GPA. The absence of the relationship between it and the current GPA suggests that it could not serve as an indicator of short-term academic performance.

These findings observed here collectively demonstrate the importance of using a longitudinal design to examine whether sleep activity predicts future academic performance. Early work has already tried to examine this issue [59-63]. Three studies reported significant associations between sleep and long-term academic performance $[59,60,63]$, whereas two studies did not [61,62]. These studies employed self-report or parent/teacher-report questionnaires to estimate sleep activity and academic performance [63]. Here, we endorse objective sleep measures estimated by wearable devices.

Limitations of the current study need to be pointed out. First, the sample size $(n=45)$ was relatively small. Using wearable devices similar to those used in the current study, Okano et al. [43] analyzed sleep data from 88 college students. Results from studies with a sample size much larger than the current study are needed to verify the findings observed here. Second, in order not to overwhelm the participants by having them complete daily lengthy questionnaires, and also to ensure the participants could continue to provide reliable feedback, we employed a simplified in-house questionnaire with only a few items to probe into the different aspects of sleep activity. Previous studies have used the Pittsburgh Sleep Quality Index [64] to estimate sleep quality and duration, and the Epworth Sleepiness Scale [86] to estimate daytime sleepiness. Each of the two has multiple items, and provides different sub-measures, and they have been widely used in sleep studies. The in-house questionnaire used here may not be representative, and could not capture the multi-facets of sleep. Future studies with comprehensive questionnaires are needed. Third, other measures, such as students' mental health (e.g., subclinical depression and anxiety), were 
not collected in and after the sleep tracking period. The relationships between sleep and academic performance may have been influenced by these factors $[79,80,87,88]$. Personality traits (e.g., Type D) and physical and sleep characteristics (e.g., Body Mass Index, snoring, and obstructive sleep apnea) also contribute to sleep quality and disturbances [89-91]. Complex relationships among them can be further explored in future studies. Finally, the current longitudinal study did not collect data on students' sleep activity measured by wearable devices and self-report questionnaires across the entire college education. It will be important to examine whether nighttime sleep awakening frequency, self-reported daytime wakefulness, and sleep quality persist after the sleep tracking period, and whether their consistency predicts academic performance [63].

\section{Conclusions}

Using wearable smartwatches and a self-report questionnaire, we provide evidence that nighttime sleep awakening frequency and its consistency can predict long-term academic performance, and self-reported daytime wakefulness and sleep quality can serve as indicators of academic performance. This study demonstrates the usefulness of employing a longitudinal design to examine how sleep activity predicts future academic performance.

Author Contributions: Conceptualization, G.W.H. and Y.L.; Data curation, Z.Y., L.X., K.K.-T.T. and Y.L.; Formal analysis, Y.L.; Funding acquisition, G.W.H. and Y.L.; Investigation, Z.Y., L.X., K.K.-T.T. and H.D.R.; Methodology, G.W.H., Z.Y., L.X., K.K.-T.T., H.D.R. and Y.L.; Project administration, G.W.H., K.K.-T.T. and Y.L.; Resources, G.W.H.; Software, Y.L.; Supervision, G.W.H.; Visualization, Y.L.; Writing—original draft, G.W.H. and Y.L.; Writing—review and editing, G.W.H., H.D.R. and Y.L. All authors have read and agreed to the published version of the manuscript.

Funding: This research was funded by BNU-HKBU United International College Research Grant (R202619, R202011, R202102, R5202018, R201805, R6014), the Humanities and Social Sciences Fund of Ministry of Education of China (20YJCZH079), and Guangdong Province High Education Key Platform and Research Project 2020 (2020ZDZX1022).

Institutional Review Board Statement: The study was conducted according to the guidelines of the Declaration of Helsinki, and approved by the Human Research Ethics Committee of BNU-HKBU United International College (code, not applicable; date of approval, 20 October 2017).

Informed Consent Statement: Informed consent was obtained from all subjects involved in the study.

Data Availability Statement: Data are available upon request.

Acknowledgments: We thank all the students for participating in this study.

Conflicts of Interest: The authors declare no conflict of interest.

\section{References}

1. Hobson, J.A.; Pace-Schott, E.F. The cognitive neuroscience of sleep: Neuronal systems, consciousness and learning. Nat. Rev. Neurosci. 2002, 3, 679-693. [CrossRef]

2. Colrain, I.M.; Baker, F.C. Changes in sleep as a function of adolescent development. Neuropsychol. Rev. 2011, 21, 5-21. [CrossRef]

3. Astill, R.G.; Van der Heijden, K.B.; Van Ijzendoorn, M.H.; Van Someren, E.J. Sleep, cognition, and behavioral problems in school-age children: A century of research meta-analyzed. Psychol. Bull. 2012, 138, 1109-1138. [CrossRef]

4. Tarokh, L.; Saletin, J.M.; Carskadon, M.A. Sleep in adolescence: Physiology, cognition and mental health. Neurosci. Biobehav. Rev. 2016, 70, 182-188. [CrossRef]

5. Hudson, A.N.; Van Dongen, H.P.A.; Honn, K.A. Sleep deprivation, vigilant attention, and brain function: A review. Neuropsychopharmacology 2020, 45, 21-30. [CrossRef]

6. Fenn, K.M.; Nusbaum, H.C.; Margoliash, D. Consolidation during sleep of perceptual learning of spoken language. Nature 2003, 425, 614-616. [CrossRef]

7. Stickgold, R. Sleep-dependent memory consolidation. Nature 2005, 437, 1272-1278. [CrossRef]

8. Walker, M.P.; Stickgold, R. Overnight alchemy: Sleep-dependent memory evolution. Nat. Rev. Neurosci. 2010, 11, 218. [CrossRef]

9. Pilcher, J.J.; Huffcutt, A.I. Effects of sleep deprivation on performance: A meta-analysis. Sleep 1996, 19, 318-326. [CrossRef]

10. Alhola, P.; Polo-Kantola, P. Sleep deprivation: Impact on cognitive performance. Neuropsychiatr. Dis. Treat. 2007, 3, 553-567.

11. Ratcliff, R.; Van Dongen, H.P. Sleep deprivation affects multiple distinct cognitive processes. Psychon. Bull. Rev. 2009, 16, 742-751. [CrossRef] 
12. Killgore, W.D. Effects of sleep deprivation on cognition. Prog. Brain Res. 2010, 185, 105-129. [CrossRef]

13. McCoy, J.G.; Strecker, R.E. The cognitive cost of sleep lost. Neurobiol. Learn. Mem. 2011, 96, 564-582. [CrossRef]

14. de Bruin, E.J.; van Run, C.; Staaks, J.; Meijer, A.M. Effects of sleep manipulation on cognitive functioning of adolescents: A systematic review. Sleep Med. Rev. 2017, 32, 45-57. [CrossRef]

15. van Dijk, D.M.; van Rhenen, W.; Murre, J.M.J.; Verwijk, E. Cognitive functioning, sleep quality, and work performance in non-clinical burnout: The role of working memory. PLoS ONE 2020, 15, e231906. [CrossRef]

16. Lim, J.; Dinges, D.F. A meta-analysis of the impact of short-term sleep deprivation on cognitive variables. Psychol. Bull. 2010, 136, 375-389. [CrossRef]

17. Drummond, S.P.; Brown, G.G. The effects of total sleep deprivation on cerebral responses to cognitive performance. Neuropsychopharmacology 2001, 25, S68-S73. [CrossRef]

18. Chee, M.W.; Chuah, L.Y. Functional neuroimaging insights into how sleep and sleep deprivation affect memory and cognition. Curr. Opin. Neurol. 2008, 21, 417-423. [CrossRef]

19. Wulff, K.; Gatti, S.; Wettstein, J.G.; Foster, R.G. Sleep and circadian rhythm disruption in psychiatric and neurodegenerative disease. Nat. Rev. Neurosci. 2010, 11, 589-599. [CrossRef]

20. Spira, A.P.; Chen-Edinboro, L.P.; Wu, M.N.; Yaffe, K. Impact of sleep on the risk of cognitive decline and dementia. Curr. Opin. Psychiatry 2014, 27, 478-483. [CrossRef]

21. Ju, Y.E.; Lucey, B.P.; Holtzman, D.M. Sleep and Alzheimer disease pathology-A bidirectional relationship. Nat. Rev. Neurol. 2014, 10, 115-119. [CrossRef]

22. Krause, A.J.; Simon, E.B.; Mander, B.A.; Greer, S.M.; Saletin, J.M.; Goldstein-Piekarski, A.N.; Walker, M.P. The sleep-deprived human brain. Nat. Rev. Neurosci. 2017, 18, 404-418. [CrossRef]

23. Spruyt, K. Neurocognitive Effects of Sleep Disruption in Children and Adolescents. Child Adolesc. Psychiatr. Clin. N. Am. 2021, 30, 27-45. [CrossRef]

24. Liu, X.; Liu, L.; Owens, J.A.; Kaplan, D.L. Sleep patterns and sleep problems among schoolchildren in the United States and China. Pediatrics 2005, 115, 241-249. [CrossRef]

25. Owens, J. Classification and epidemiology of childhood sleep disorders. Prim. Care. 2008, 35, 533-546. [CrossRef]

26. Williamson, A.A.; Mindell, J.A.; Hiscock, H.; Quach, J. Child sleep behaviors and sleep problems from infancy to school-age. Sleep Med. 2019, 63, 5-8. [CrossRef]

27. Consensus Conference Panel; Watson, N.F.; Badr, M.S.; Belenky, G.; Bliwise, D.L.; Buxton, O.M.; Buysse, D.; Dinges, D.F.; Gangwisch, J.; Grandner, M.A.; et al. Recommended Amount of Sleep for a Healthy Adult: A Joint Consensus Statement of the American Academy of Sleep Medicine and Sleep Research Society. J. Clin. Sleep Med. 2015, 11, 591-592. [CrossRef]

28. Lund, H.G.; Reider, B.D.; Whiting, A.B.; Prichard, J.R. Sleep patterns and predictors of disturbed sleep in a large population of college students. J. Adolesc. Health 2010, 46, 124-132. [CrossRef] [PubMed]

29. Orzech, K.M.; Salafsky, D.B.; Hamilton, L.A. The state of sleep among college students at a large public university. J. Am. Coll. Health 2011, 59, 612-619. [CrossRef]

30. Becker, S.P.; Jarrett, M.A.; Luebbe, A.M.; Garner, A.A.; Burns, G.L.; Kofler, M.J. Sleep in a large, multi-university sample of college students: Sleep problem prevalence, sex differences, and mental health correlates. Sleep Health 2018, 4, 174-181. [CrossRef]

31. Curcio, G.; Ferrara, M.; De Gennaro, L. Sleep loss, learning capacity and academic performance. Sleep Med. Rev. 2006, 10, 323-337. [CrossRef]

32. Dewald, J.F.; Meijer, A.M.; Oort, F.J.; Kerkhof, G.A.; Bogels, S.M. The influence of sleep quality, sleep duration and sleepiness on school performance in children and adolescents: A meta-analytic review. Sleep Med. Rev. 2010, 14, 179-189. [CrossRef] [PubMed]

33. Prichard, J.R. Sleep Predicts Collegiate Academic Performance: Implications for Equity in Student Retention and Success. Sleep Med. Clin. 2020, 15, 59-69. [CrossRef] [PubMed]

34. Soh, K.C. Grade point average: What's wrong and what's the alternative? J. High. Educ. Policy Manag. 2010, 33, 27-36. [CrossRef]

35. Richardson, M.; Abraham, C.; Bond, R. Psychological correlates of university students' academic performance: A systematic review and meta-analysis. Psychol. Bull. 2012, 138, 353-387. [CrossRef]

36. Hershner, S. Sleep and academic performance: Measuring the impact of sleep. Curr. Opin. Behav. Sci. 2020, 33, 51-56. [CrossRef]

37. Shochat, T.; Cohen-Zion, M.; Tzischinsky, O. Functional consequences of inadequate sleep in adolescents: A systematic review. Sleep Med. Rev. 2014, 18, 75-87. [CrossRef]

38. Wolfson, A.R.; Carskadon, M.A. Sleep schedules and daytime functioning in adolescents. Child Dev. 1998, 69, 875-887. [CrossRef]

39. Kelly, W.E.; Kelly, K.E.; Clanton, R.C. The relationship between sleep length and grade-point average among college students. Coll. Stud. J. 2001, 35, 84-86.

40. Ng, E.P.; Ng, D.K.; Chan, C.H. Sleep duration, wake/sleep symptoms, and academic performance in Hong Kong Secondary School Children. Sleep Breath. 2009, 13, 357-367. [CrossRef]

41. Taylor, D.J.; Vatthauer, K.E.; Bramoweth, A.D.; Ruggero, C.; Roane, B. The role of sleep in predicting college academic performance: Is it a unique predictor? Behav. Sleep Med. 2013, 11, 159-172. [CrossRef]

42. Mirghani, H.O.; Mohammed, O.S.; Almurtadha, Y.M.; Ahmed, M.S. Good sleep quality is associated with better academic performance among Sudanese medical students. BMC Res. Notes 2015, 8, 706. [CrossRef]

43. Okano, K.; Kaczmarzyk, J.R.; Dave, N.; Gabrieli, J.D.E.; Grossman, J.C. Sleep quality, duration, and consistency are associated with better academic performance in college students. NPJ Sci. Learn. 2019, 4, 16. [CrossRef] 
44. Sridhar, H.S.K.; Kimble, A.; King, M.M.; Johnson, C.P.; Shah, R.J.; Dietzel, J.M.; Yoo, C.H.; Moreno, M.P.; Pant, P.; Edwards, J.A.; et al. Lower sleep variability associated with higher academic performance across the semester in college students. PsyArxiv 2019.

45. Dokuka, S.; Smirnov, I. High academic performance is associated with shorter sleep and later bedtimes for young adults. arXiv 2020, arXiv:2005.07806.

46. Gomes, A.A.; Tavares, J.; de Azevedo, M.H. Sleep and academic performance in undergraduates: A multi-measure, multi-predictor approach. Chronobiol. Int. 2011, 28, 786-801. [CrossRef]

47. Ahrberg, K.; Dresler, M.; Niedermaier, S.; Steiger, A.; Genzel, L. The interaction between sleep quality and academic performance. J. Psychiatr. Res. 2012, 46, 1618-1622. [CrossRef]

48. Lemma, S.; Berhane, Y.; Worku, A.; Gelaye, B.; Williams, M.A. Good quality sleep is associated with better academic performance among university students in Ethiopia. Sleep Breath. 2014, 18, 257-263. [CrossRef]

49. Önder, İ.B.; Beşoluk, Ş.; İskender, M.; Masal, E.; Demirhan, E. Circadian preferences, sleep quality and sleep patterns, personality, academic motivation and academic achievement of university students. Learn. Individ. Differ. 2014, 32, 184-192. [CrossRef]

50. Adelantado-Renau, M.; Beltran-Valls, M.R.; Migueles, J.H.; Artero, E.G.; Legaz-Arrese, A.; Capdevila-Seder, A.; Moliner-Urdiales, D. Associations between objectively measured and self-reported sleep with academic and cognitive performance in adolescents: DADOS study. J. Sleep Res. 2019, 28, e12811. [CrossRef]

51. Maheshwari, G.; Shaukat, F. Impact of Poor Sleep Quality on the Academic Performance of Medical Students. Cureus 2019, 11, e4357. [CrossRef] [PubMed]

52. Genzel, L.; Ahrberg, K.; Roselli, C.; Niedermaier, S.; Steiger, A.; Dresler, M.; Roenneberg, T. Sleep timing is more important than sleep length or quality for medical school performance. Chronobiol. Int. 2013, 30, 766-771. [CrossRef]

53. Phillips, A.J.K.; Clerx, W.M.; O’Brien, C.S.; Sano, A.; Barger, L.K.; Picard, R.W.; Lockley, S.W.; Klerman, E.B.; Czeisler, C.A. Irregular sleep/wake patterns are associated with poorer academic performance and delayed circadian and sleep/wake timing. Sci. Rep. 2017, 7, 3216. [CrossRef]

54. Chen, W.L.; Chen, J.H. Consequences of inadequate sleep during the college years: Sleep deprivation, grade point average, and college graduation. Prev. Med. 2019, 124, 23-28. [CrossRef]

55. Haraszti, R.A.; Ella, K.; Gyongyosi, N.; Roenneberg, T.; Kaldi, K. Social jetlag negatively correlates with academic performance in undergraduates. Chronobiol. Int. 2014, 31, 603-612. [CrossRef] [PubMed]

56. Lee, M.S.; Shin, J.S.; Lee, J.; Lee, Y.J.; Kim, M.R.; Park, K.B.; Shin, D.; Cho, J.H.; Ha, I.H. The association between mental health, chronic disease and sleep duration in Koreans: A cross-sectional study. BMC Public Health 2015, 15, 1200. [CrossRef] [PubMed]

57. Diaz-Morales, J.F.; Escribano, C. Social jetlag, academic achievement and cognitive performance: Understanding gender/sex differences. Chronobiol. Int. 2015, 32, 822-831. [CrossRef]

58. Smarr, B.L. Digital sleep logs reveal potential impacts of modern temporal structure on class performance in different chronotypes. J. Biol. Rhythms 2015, 30, 61-67. [CrossRef] [PubMed]

59. Wong, M.L.; Lau, E.Y.; Wan, J.H.; Cheung, S.F.; Hui, C.H.; Mok, D.S. The interplay between sleep and mood in predicting academic functioning, physical health and psychological health: A longitudinal study. J. Psychosom. Res. 2013, 74, 271-277. [CrossRef]

60. Galambos, N.L.; Vargas Lascano, D.I.; Howard, A.L.; Maggs, J.L. Who sleeps best? Longitudinal patterns and covariates of change in sleep quantity, quality, and timing across four university years. Behav. Sleep Med. 2013, 11, 8-22. [CrossRef]

61. Tavernier, R.; Willoughby, T. Bidirectional associations between sleep (quality and duration) and psychosocial functioning across the university years. Dev. Psychol. 2014, 50, 674-682. [CrossRef]

62. Faught, E.L.; Qian, W.; Carson, V.L.; Storey, K.E.; Faulkner, G.; Veugelers, P.J.; Leatherdale, S.T. The longitudinal impact of diet, physical activity, sleep, and screen time on Canadian adolescents' academic achievement: An analysis from the COMPASS study. Prev. Med. 2019, 125, 24-31. [CrossRef]

63. Stormark, K.M.; Fosse, H.E.; Pallesen, S.; Hysing, M. The association between sleep problems and academic performance in primary school-aged children: Findings from a Norwegian longitudinal population-based study. PLoS ONE 2019, 14, e0224139. [CrossRef]

64. Buysse, D.J.; Reynolds, C.F., 3rd; Monk, T.H.; Berman, S.R.; Kupfer, D.J. The Pittsburgh Sleep Quality Index: A new instrument for psychiatric practice and research. Psychiatry Res. 1989, 28, 193-213. [CrossRef]

65. Hertenstein, E.; Gabryelska, A.; Spiegelhalder, K.; Nissen, C.; Johann, A.F.; Umarova, R.; Riemann, D.; Baglioni, C.; Feige, B. Reference Data for Polysomnography-Measured and Subjective Sleep in Healthy Adults. J. Clin. Sleep Med. 2018, 14, 523-532. [CrossRef]

66. Boulos, M.I.; Jairam, T.; Kendzerska, T.; Im, J.; Mekhael, A.; Murray, B.J. Normal polysomnography parameters in healthy adults: A systematic review and meta-analysis. Lancet Respir. Med. 2019, 7, 533-543. [CrossRef]

67. Sadeh, A.; Pergamin, L.; Bar-Haim, Y. Sleep in children with attention-deficit hyperactivity disorder: A meta-analysis of polysomnographic studies. Sleep Med. Rev. 2006, 10, 381-398. [CrossRef]

68. Baglioni, C.; Regen, W.; Teghen, A.; Spiegelhalder, K.; Feige, B.; Nissen, C.; Riemann, D. Sleep changes in the disorder of insomnia: A meta-analysis of polysomnographic studies. Sleep Med. Rev. 2014, 18, 195-213. [CrossRef]

69. Baglioni, C.; Nanovska, S.; Regen, W.; Spiegelhalder, K.; Feige, B.; Nissen, C.; Reynolds, C.F.; Riemann, D. Sleep and mental disorders: A meta-analysis of polysomnographic research. Psychol. Bull. 2016, 142, 969-990. [CrossRef] 
70. Miller, N.L.; Shattuck, L.G.; Matsangas, P. Longitudinal study of sleep patterns of United States Military Academy cadets. Sleep 2010, 33, 1623-1631. [CrossRef]

71. Beattie, Z.; Oyang, Y.; Statan, A.; Ghoreyshi, A.; Pantelopoulos, A.; Russell, A.; Heneghan, C. Estimation of sleep stages in a healthy adult population from optical plethysmography and accelerometer signals. Physiol. Meas. 2017, 38, 1968-1979. [CrossRef]

72. de Arriba-Pérez, F.; Caeiro-Rodríguez, M.; Santos-Gago, J.M. How do you sleep? Using off the shelf wrist wearables to estimate sleep quality, sleepiness level, chronotype and sleep regularity indicators. J. Ambient. Intell. Humaniz. Comput. 2018, 9, 897-917. [CrossRef]

73. Wang, J.-S.; Gamble, J.H.; Yang, Y.-T.C. Mobile sensor-based community gaming for improving vocational students' sleep and academic outcomes. Comput. Educ. 2020, 151, 103812. [CrossRef]

74. Guo, Y.; Wang, H.; Zhang, H.; Liu, T.; Liang, Z.; Xia, Y.; Yan, L.; Xing, Y.; Shi, H.; Li, S.; et al. Mobile Photoplethysmographic Technology to Detect Atrial Fibrillation. J. Am. Coll. Cardiol. 2019, 74, 2365-2375. [CrossRef]

75. Guo, Y.; Lane, D.A.; Wang, L.; Chen, Y.; Lip, G.Y.H.; On behalf of the mAF-App II Trial, investigators. Mobile Health (mHealth) technology for improved screening, patient involvement and optimising integrated care in atrial fibrillation: The mAFA (mAFApp) II randomised trial. Int. J. Clin. Pract. 2019, 73, e13352. [CrossRef]

76. Kinast, B.; Lutz, M.; Schreiweis, B. Telemonitoring of Real-World Health Data in Cardiology: A Systematic Review. Int. J. Environ. Res. Public Health 2021, 18, 9070. [CrossRef]

77. Hayes, A.F. PROCESS: A Versatile Computational Tool for Observed Variable Mediation, Moderation, and Conditional Process Modeling [White Paper]. 2012. Available online: http:/ / www.afhayes.com/public/process2012 (accessed on 20 December 2021).

78. Gupta, R.; Bhatia, M.S.; Chhabra, V.; Sharma, S.; Dahiya, D.; Semalti, K.; Sapra, R.; Dua, R.S. Sleep patterns of urban school-going adolescents. Indian Pediatr. 2008, 45, 183-189.

79. El-Sheikh, M.; Buckhalt, J.A.; Mark Cummings, E.; Keller, P. Sleep disruptions and emotional insecurity are pathways of risk for children. J. Child Psychol. Psychiatry 2007, 48, 88-96. [CrossRef]

80. Velten-Schurian, K.; Hautzinger, M.; Poets, C.F.; Schlarb, A.A. Association between sleep patterns and daytime functioning in children with insomnia: The contribution of parent-reported frequency of night waking and wake time after sleep onset. Sleep Med. 2010, 11, 281-288. [CrossRef]

81. Ting, H.; Wong, R.H.; Yang, H.J.; Lee, S.P.; Lee, S.D.; Wang, L. Sleep-disordered breathing, behavior, and academic performance in Taiwan schoolchildren. Sleep Breath. 2011, 15, 91-98. [CrossRef]

82. Valic, M.; Pecotic, R.; Lusic, L.; Peros, K.; Pribudic, Z.; Dogas, Z. The relationship between sleep habits and academic performance in dental students in Croatia. Eur. J. Dent. Educ. 2014, 18, 187-194. [CrossRef] [PubMed]

83. Forquer, L.M.; Camden, A.E.; Gabriau, K.M.; Johnson, C.M. Sleep patterns of college students at a public university. J. Am. Coll. Health 2008, 56, 563-565. [CrossRef] [PubMed]

84. Bahammam, A.S.; Alaseem, A.M.; Alzakri, A.A.; Almeneessier, A.S.; Sharif, M.M. The relationship between sleep and wake habits and academic performance in medical students: A cross-sectional study. BMC Med. Educ. 2012, 12, 61. [CrossRef] [PubMed]

85. Datta, A.; Nag, K.; Karmakar, N.; Chakrabarty, T.; Tripura, K.; Bhattacharjee, P. Sleep disturbance and its effect on academic performance among students of a medical college of Tripura. Int. J. Community Med. Public Health 2019, 6, 293-298. [CrossRef]

86. Johns, M.W. A new method for measuring daytime sleepiness: The Epworth sleepiness scale. Sleep 1991, 14, 540-545. [CrossRef]

87. Brand, S.; Lemola, S.; Holsboer-Trachsler, E.; Grob, A.; Kalak, N. Sleep duration and subjective psychological well-being in adolescence: A longitudinal study in Switzerland and Norway. Neuropsychiatr. Dis. Treat. 2014, 10, 1199-1207. [CrossRef]

88. Williamson, A.A.; Mindell, J.A.; Hiscock, H.; Quach, J. Longitudinal sleep problem trajectories are associated with multiple impairments in child well-being. J. Child Psychol. Psychiatry 2020, 61, 1092-1103. [CrossRef]

89. Akram, U.; McCarty, K.; Akram, A.; Gardani, M.; Tan, A.; Villarreal, D.; Bilsborough, E.; Dooher, G.; Gibbs, G.; Hudson, J.L.; et al. The relationship between Type D personality and insomnia. Sleep Health 2018, 4, 360-363. [CrossRef]

90. Sella, E.; Carbone, E.; Toffalini, E.; Borella, E. Personality traits and sleep quality: The role of sleep-related beliefs. Pers. Individ. Dif. 2020, 156, 109770. [CrossRef]

91. Dalewski, B.; Kamińska, A.; Syrico, A.; Kałdunska, A.; Pałka, L.; Sobolewska, E. The Usefulness of Modified Mallampati Score and CT Upper Airway Volume Measurements in Diagnosing OSA among Patients with Breathing-Related Sleep Disorders. Appl. Sci. 2021, 11, 3764. [CrossRef] 